\title{
VARIABLES PREDICTIVE OF VOIDING DISFUNCTION FOLLOWING APONEUROTIC SLING SURGERY: MULTIVARIATE ANALYSIS
}

\author{
SÍLVIO H.M. DE ALMEIDA, ÉMERSON GREGÓRIO, SAWLA EL SAYED, FREDERICO C. \\ FRAGA, HORÁCIO A. MOREIRA, MARCO A.F. RODRIGUES
}

\author{
Sector of Urology, Department of Surgery, State University of Londrina, Paraná, Brazil
}

\begin{abstract}
Introduction: Aponeurotic sling surgeries can evolve with obstruction or voiding dysfunction in 5 to $20 \%$ of patients. There are few studies on factors that could possibly predispose to voiding difficulties or urinary retention. The objective of this work is to identify these potential clinical or urodynamic factors.

Materials and Methods: Records from 130 patients who underwent aponeurotic sling surgeries were reviewed. All patients underwent a throughout urodynamic study during pre-operative investigation. The variables studied were age above 65 years, previous pelvic surgeries, concomitant surgeries, post-voiding residue higher than $100 \mathrm{~mL}$, vesical obstruction (according to Blaivas-Groutz nomogram) and urinary flow under $12 \mathrm{~mL} / \mathrm{s}$. Post-voiding residue was assessed on the seventh postoperative day through vesical catheterization. Recovering of spontaneous voiding after 7 post-operative days or with a residue higher than $100 \mathrm{~mL}$, was regarded as voiding dysfunction. Univariate analysis was performed with qui-square test and Fisher's exact test, and multivariate analysis was performed by logistic regression with $\alpha=5 \%$.

Results: Age in the studied group ranged from 41 to 83 years (mean 56.7 years), with 69 (53\%) patients having urethral hypermobility and 61 (47\%) having intrinsic urethral lesion. Normal voiding occurred in $97(75.6 \%)$ women with 7 post-operative days. The only significant variable in the univariate $(\mathrm{p}=0.014)$ and multivariate $(\mathrm{p}=0.017)$ analysis was post-voiding residue higher than $100 \mathrm{~mL}$

Conclusion: Pre-operative presence of a post-voiding residual urine higher than $100 \mathrm{~mL}$ was the only variable predictive of voiding dysfunction.
\end{abstract}

Key words: urinary incontinence; surgery; voiding dysfunction; urethra; bladder

Int Braz J Urol. 2004; 30: 302-6

\section{INTRODUCTION}

Pubovaginal sling surgery has been used for treating urinary incontinence due to sphincteric lesion for decades and with good results (1). Some years ago, some reports showed up demonstrating good results for all types of female stress urinary incontinence as well (2-4). This major indication of the tech- nique has been accompanied by incidences of prolonged urinary retention of 5 to $20 \%$ (4-6).

The urethrovesical junction undergoes, due to the fibrotic process, a change in position during the postoperative period for synthetic and autologous slings (7). Such change could exert an obstructive effect on the urethra, increasing voiding pressure and decreasing the urinary flow, which could explain the 
outcome with retention. However, videourodynamic studies have demonstrated that a band carefully place with no tension, would not have an obstructive effect $(8,9)$.

A number of factors are suggested as carrying a risk for voiding dysfunction, such as advanced age, concomitant surgeries, previous surgeries for urinary incontinence, urinary flow below $12 \mathrm{~mL} / \mathrm{s}$, large post-voiding residual urine and voiding with low contractility or with Valsalva's maneuver, among others $(6,10-13)$.

The objective of this study is to analyze the importance of some of these clinical and urodynamic factors for predicting the difficulty to obtain normal voiding following aponeurotic sling surgeries, using multivariate analysis.

\section{MATERIALS AND METHODS}

One hundred and thirty patients with urinary incontinence due to urethral hypermobility or intrinsic sphincteric lesion, who underwent sling surgery with aponeurosis of the rectus muscle of abdomen, between 1998 and 2003, had their medical records reviewed. All patients underwent a throughout urodynamic study with 2 vesical fillings previously to surgery.

The exam was performed according to the standards of the International Continence Society, using $0.9 \%$ saline solution at a temperature of $37^{\circ}$ Celsius, with a 7F two-way urethral catheter and a $10 \mathrm{~F}$ rectal catheter (14).

The abdominal leak point pressure under stress was measured at half cystometric capacity, in upright position, with the presence of a $7 \mathrm{~F}$ two-way catheter inside the urethra, considering the lowest value for vesical pressure in the absence of detrusor contraction (15). Patients were initially asked to perform repeated Valsalva's maneuvers for 3 times. In the absence of leakage with Valsalva, the patient was asked to cough. Those patients with abdominal leak point pressure under stress above $60 \mathrm{~cm}$ of $\mathrm{H}_{2} \mathrm{O}$ were regarded as having urinary incontinence with some degree of urethral hypermobility.

The same surgeon performed all surgeries, using segments of aponeurosis of the rectus abdomi- nal muscle measuring approximately $2 \mathrm{~cm} \times 7 \mathrm{~cm}$ and with Pfanestiel-type incisions in the abdomen and elliptical incision in the vagina. A forceps was interposed between the urethra and the tape at the moment of tying the threads, in order to avoid any compression over the urethra.

The clinical variables analyzed were age above 65 years, performance of previous surgery for urinary incontinence, performance of other pelvic procedure concomitantly to the surgery, presence of debilitating neuropathic or chronic diseases, and the mechanism of urinary incontinence (urethral hypermobility or sphincteric lesion).

The pre-operative urodynamic variables studied were peak free urinary flow below $12 \mathrm{~mL} / \mathrm{s}$, residual urine on voiding cystometry (without abdominal stress) higher than $100 \mathrm{~mL}$, and the presence of obstruction superior or equal to moderate type in the Blaivas-Groutz nomogram for female obstruction (16).

On the first post-operative day, the bladder was filled, the catheter was removed and voiding was observed for 6 hours. In the absence of retention, patients were discharged from the hospital. If clinically required, they remained at the hospital, however without catheter.

In case of retention, patients were catheterized again for 3 days, when the process of catheter removal was repeated. On the seventh post-operative day, post-voiding residual urine was assessed through vesical catheterization, in all patients. Late voiding was considered when there was a post-voiding residual urine higher than $100 \mathrm{~mL} 7$ days after surgery. The variables were studied through univariate analysis (qui-square and Fisher's exact tests) and multivariate analysis with logistic regression.

\section{RESULTS}

Age in the group under study ranged from 41 to 83 years (mean 56.7 years), with $69(53 \%)$ patients having urethral hypermobility and $61(47 \%)$ having urethral lesion, and $97(75.6 \%)$ presented normal voiding within 7 days postoperatively. Three patients $(2.3 \%)$ required urethrolysis due to prolonged retention. 
Table 1 - Frequency of observed variables.

\begin{tabular}{lcc}
\hline Variable & Frequency & \% \\
\hline Presence of other diseases & 62 & 47.7 \\
Previous surgeries & 89 & 68.5 \\
Concomitant surgeries & 45 & 34.6 \\
Age above 65 years & 50 & 38.5 \\
Urethral hypermobility & 69 & 53.1 \\
Urinary flow < $12 \mathrm{~mL} / \mathrm{s}$ & 26 & 20.0 \\
Obstruction & 20 & 15.4 \\
Residual urine $>100 \mathrm{~mL}$ & 67 & 51.5 \\
\hline
\end{tabular}

Table- 1 shows the frequencies for each variable. Table- 2 demonstrates the results obtained in univariate analysis, with the only significant variable being post-voiding residual urine, which was also observed in the multivariate analysis $(\mathrm{p}=0.017)$.

A post-voiding residual urine superior to 100 $\mathrm{mL}$ occurred in 67 patients, and 16 of them were obstructed, 22 had large prolapses, 15 presented contractility deficiency, and in 14 it was not possible to suppose any cause for the increased residual urine.

\section{COMMENTS}

Even if videourodynamics does not demonstrate obstruction following sling surgeries, the literature stresses that decreasing the tape tension reduces the risk of voiding dysfunction, but reduces therapeutic efficacy as well. Flood et al.(17) compared the presence of early voiding dysfunction in 2 groups where the only variable was tape tension. Voiding efficiency (smallest post-voiding residue) was significantly lowest in the group of tension-free tapes, however the failure indexes (any leakage at 3 months after surgery) were also significantly higher in this group (17). Petrou \& Broderick demonstrated that urethral position changes in a retropubic direction after surgery, and that occurs progressively as the remodeling of aponeurotic tape takes place (18). Such change would lead to the necessity of voiding adaptation, which would be more efficient and prompter depending on each patient's functional characteristics.

Voiding with weak detrusor contraction or with Valsalva's maneuver has been associated with a higher risk of urinary retention and even surgical failure $(12,19,20)$. Miller et al. (12) observed that of 21 women that voided without contraction on the preoperative test, 4 (23\%) presented postoperative urinary retention, versus none among other 48 women with normal contraction. Still in the same study, no patient with contraction superior to $12 \mathrm{~cm}$ of $\mathrm{H}_{2} \mathrm{O}$ presented retention.

Among the parameters tested for voiding dysfunction, only the post-voiding residue was a significant factor. However, the authors stress that the small sample limits the conclusions of the study (12).

Voiding residue can be an indicator of voiding efficiency, either achieved by Valsalva's maneuver or by effective detrusor contraction. Its pre-operative presence, due to loss of contractility, obstruction, or both, can mean a demonstration of such efficiency loss, and consequently, a risk factor for postoperative voiding dysfunction.

We could not find in literature another work that studied, exclusively in sling surgeries, the risk factors for voiding dysfunction using multivariate statis-

Table 2 - Univariate analysis for different risk factors.

\begin{tabular}{lccc}
\hline & Relative Risk & Confidence Interval & p Value \\
\hline Concomitant diseases & 0.99 & $0.610-1.614$ & 0.891 \\
Previous surgeries & 1.89 & $1.010-3.535$ & 0.052 \\
Concomitant surgeries & 1.45 & $0.899-2.361$ & 0.183 \\
Age above 65 years & 1.24 & $0.771-2.024$ & 0.462 \\
Urethral hypermobility & 0.78 & $0.486-1.277$ & 0.422 \\
Urinary flow $<12 \mathrm{~mL} / \mathrm{s}$ & 1.48 & $0.886-2.481$ & 0.211 \\
Urinary obstruction & 1.51 & $0.887-2.591$ & 0.213 \\
Residual urine $>100 \mathrm{~mL}$ & 2.00 & $1.158-3.486$ & 0.014 \\
\hline
\end{tabular}


tical analysis. Kobak et al. (13) studied 3 groups of patients undergoing Burch surgery, anterior colporrhaphy and vaginal wall sling with multivariate analysis, and observed that advanced age, previous cystopexy, larger vesical volume on the first voiding desire and high post-voiding residual urine were risk factors for postoperative voiding dysfunction. The authors did not associate pre-operative voiding mechanism, intensity of contraction and use of Valsalva's maneuver, with risk of voiding dysfunction. The closest comparison to our group of patients would be only those 34 sling surgeries performed in this study, even if they were made on the vaginal wall. However, the type of surgery was not stratified by the authors (13).

Advanced age is the clinical information most frequently related to the risk of urinary retention following aponeurotic sling surgeries and even following "tension-free vaginal tape" (TVT), probably due to the higher risk of dysfunctional pelvic nervous plexuses and detrusor muscle $(6,19)$. In this work, clinical factors were not predictive of voiding difficulties, reinforcing the theory that pre-operative urodynamic results are more important.

There is no universally accepted urodynamic criterion for diagnosing vesical obstruction in women. We used the Blaivas-Groutz nomogram, which classifies the obstruction levels in non-obstructed, slightly obstructed, moderately and severely obstructed (6). However this nomogram has not been shown able to predict postoperative dysfunction. In a randomized study between Burch surgery and TVT, it was observed that the nomogram did not show differences either between patients with objective cure of incontinence, failure or voiding dysfunction in both groups (20).

The methodology used in trials, usually retrospective, with limited statistical methods and samples, as well as different definitions of urinary retention and voiding dysfunction, grouping different types of surgery, explain the discordant results found in literature. Though we have not studied the voiding mechanism and the presence of involuntary contractions, the statistical analysis, the sample volume, and the selection of patients who underwent surgeries with aponeurotic slings only, strengthen the results of this work.
Urethral obstruction probably is not the only causal agent, both for achieving surgical success and for postoperative voiding dysfunction. Factors related to voiding dynamic and efficacy and to changes in the periurethral collagen, may act as well. Our results reinforce the notion that the pre-operative presence of significant post-voiding residual urine is not a contra-indication for performing the aponeurotic sling; however, it alerts the surgeon to the risk of any difficulty concerning the adaptation to a new voiding dynamics and consequently the recovery of normal voiding.

\section{CONCLUSION}

Voiding residual urine above $100 \mathrm{~mL}$ was the only variable predictive of voiding dysfunction in the postoperative period of aponeurotic sling surgery in a multivariate analysis.

\section{REFERENCES}

1. McGuire EJ, Bennett CJ, Konnak JA, Sonda LP, Savastano JA: Experience with pubovaginal slings for urinary incontinence at the University of Michigan. J Urol. 1987; 138: 525-6.

2. Chaikin DC, Rosenthal J, Blaivas JG: Pubovaginal sling for all types of stress urinary incontinence: longterm analysis. J Urol. 1998; 160: 1312-6.

3. Silva-Filho AL, Triginelli SA, Noviello MB, SantosFilho AS, Pires CR, Cunha-Melo JR: Pubovaginal sling in the treatment of stress urinary incontinence for hypermobility and intrinsic sphincteric deficiency. Int Braz J Urol. 2003; 29: 540-44.

4. Morgan TO Jr, Westney OL, McGuire EJ: Pubovaginal sling: 4-year outcome analysis and quality of life assessment. J Urol. 2000; 163: 1845-8.

5. Chan PT, Fournier C, Corcos J: Short-term complications of pubovaginal sling procedure for genuine stress incontinence in women. Urology. 2000; 55: 207-11.

6. Iglesia CB, Shott S, Fenner DE, Brubaker L: Effect of preoperative voiding mechanism on success rate of autologous rectus fascia suburethral sling procedure. Obstet Gynecol. 1998; 91: 577-81.

7. Mclennan MT, Clifford FM, Cannon S: The position of the urethrovesical junction after incontinence surgery: early postoperative changes. Int Urogynecol J. 2004; 15: 44-8. 
8. Klutke JJ, Klutke CG, Bergman J, Elia G: Urodynamics changes in voiding after anti-incontinence surgery: an insight into the mechanism of cure. Urology. 1999; 54: 1003-7.

9. Kuo HC. Comparison of video urodynamic results after the pubovaginal sling procedure using rectus fascia and polypropylene mesh for stress urinary incontinence. J Urol 2001; 165: 163-8.

10. Nitti VC, TU LM, Guitlin J: Diagnosing bladder outlet obstruction in women. J Urol. 1999; 161: 1535-40.

11. Cormier L, Ferchaud J, Galas JM, Guillemin F, Mangin P: Diagnosis of female bladder outlet obstruction and relevance of the parameter area under the curve of detrusor pressure during voiding: preliminary results. J Urol. 2002; 167: 2083-7.

12. Miller EA, Amundsen CL, Toh KL, Flynn BJ, Webster GD: Preoperative urodynamic evaluation may predict voiding dysfunction in women undergoing pubovaginal sling. J Urol. 2003; 169: 2234-7.

13. Kobak WH, Walters MD, Piedmonte MR: Determinants of voiding after three types of incontinence surgery: a multivariable analysis. Obstet Gynecol. 2001; 97: 86-91.

14. Schafer W, Abrams P, Liao L, Mattiasson A, Pesce F, Spangberg A, et al.: Good urodynamic practices: uroflowmetry, filling cystometry, and pressure-flow studies. Neurourol Urodyn. 2002; 21: 261-74.
15. Abrams P, Cardozo L, Fall M, Griffiths D, Rosier P, Ulmsten U, et al.: The standardisation of terminology of lower urinary tract function: report from the standardisation sub-committee of the international continence society. Am J Obstet. Gynecol. 2002; 187: 116126.

16. Blaivas JG, Groutz A: Bladder outlet obstruction nomogram, for women with lower tract symptomatology. Neurourol. Urodyn. 2000; 19: 553-64.

17. Flood H, Muratib S, Shah A, Etisham M, Khan MS: Early voiding dysfunction and efficacy after pubovaginal sling: the role of sling tension. Aust N Z J Surg. 1998; 69: A121.

18. Petrou SP, Broderick GA. A sling is not just a backboard of urethral support. J Pelvic Surg. 2001; 7 : 11-14.

19. Mutone N, Brizendine E, Hale D: Factors that influence voiding function after the tension-free vaginal tape procedure for stress urinary incontinence. Am J Obstet Gynecol. 2003; 188: 1477-81.

20. Wang AC, Chen MC: Comparison of tension-free vaginal taping versus modified Burch colposuspension on urethral obstruction: a randomized controlled trial. Neurourol Urodyn. 2003; 22: 185-90.

\footnotetext{
Correspondence address:

Dr. Sílvio Henrique Maia de Almeida

Rua Francisco Marcelino da Silva 270

Londrina, PR, 86047-160, Brazil

Fax: + 5543 3342-9148

E-mail: salmeida@sercomtel.com.br
} 